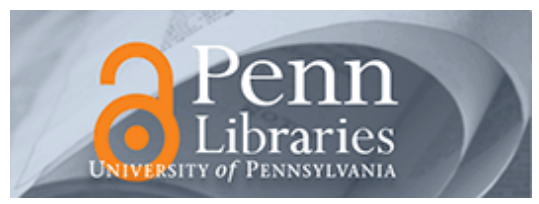

University of Pennsylvania ScholarlyCommons

$10-18-2012$

\title{
"I Didn't Know I Could Turn Colors": Health Problems and Health Care Experiences of Women Strangled by an Intimate Partner
}

Manisha Joshi

Kristie A. Thomas

Susan B. Sorenson

University of Pennsylvania, sorenson@sp2.upenn.edu

Follow this and additional works at: https://repository.upenn.edu/spp_papers

Part of the Domestic and Intimate Partner Violence Commons, Medicine and Health Commons, Medicine and Health Sciences Commons, and the Social Work Commons

\section{Recommended Citation}

Joshi, M., Thomas, K. A., \& Sorenson, S. B. (2012). "I Didn't Know I Could Turn Colors": Health Problems and Health Care Experiences of Women Strangled by an Intimate Partner. Retrieved from

https://repository.upenn.edu/spp_papers/171

Joshi, M., Thomas, K. A., \& Sorenson, S. B. (2012). "I didn't know I could turn colors": Health problems and health care experiences of women strangled by an intimate partner. Social Work in Health Care, 51(9), 798-814. doi: 10.1080/00981389.2012.692352

This paper is posted at ScholarlyCommons. https://repository.upenn.edu/spp_papers/171

For more information, please contact repository@pobox.upenn.edu. 


\title{
"I Didn't Know I Could Turn Colors": Health Problems and Health Care Experiences of Women Strangled by an Intimate Partner
}

\author{
Abstract \\ Strangulation is a unique and particularly pernicious form of intimate partner violence. To increase the \\ relatively little that is known about strangulation survivors, focus groups and interviews were conducted \\ as part of a practice-research engagement with a domestic violence shelter. All of the participants had \\ been strangled and, among them, almost all were strangled multiple times. The loss of consciousness \\ was common. Participants associated "choking" with use of body parts and "strangling" with use of \\ objects. Although some minimized the assault, most considered strangulation to be serious and reported \\ a variety of medical conditions following the assault. Few sought medical care. Of those who did, few \\ disclosed the assault, or were asked about strangulation, which commonly resulted in misdirected \\ treatment. Implications for improving detection and treatment are discussed.

\section{Keywords} \\ women, strangulation, choking, intimate partner violence, health, practice-research engagement

\section{Disciplines} \\ Domestic and Intimate Partner Violence | Medicine and Health | Medicine and Health Sciences | Social \\ Work

\section{Comments} \\ Joshi, M., Thomas, K. A., \& Sorenson, S. B. (2012). "I didn't know I could turn colors": Health problems and \\ health care experiences of women strangled by an intimate partner. Social Work in Health Care, 51(9), \\ 798-814. doi: 10.1080/00981389.2012.692352
}


Running head: INTIMATE PARTNER STRANGULATION

“I Didn't Know I Could Turn Colors": Health Problems and Health Care Experiences of Women Strangled by an Intimate Partner

\author{
Manisha Joshi, $\mathrm{PhD}$ \\ School of Social Work, University of South Florida \\ Kristie A. Thomas, PhD \\ School of Social Work, Simmons College \\ Susan B. Sorenson, PhD
}

School of Social Policy \& Practice, University of Pennsylvania

*Corresponding author:

Manisha Joshi

School of Social Work, University of South Florida

4202 East Fowler Ave, MGY132; Tampa, FL 33620-6600

Phone: (813) 974-2063; Fax: (813) 974-4675; Email: manishaj@usf.edu

\title{
Author Acknowledgments
}

We thank the staff and residents of the participating domestic violence shelter; Paola Abril Campos for her transcription help; the Moleis Family Foundation, which supported her efforts; and the Evelyn Jacobs Ortner Center for funding the study. 


\begin{abstract}
Strangulation is a unique and particularly pernicious form of intimate partner violence. To increase the relatively little that is known about strangulation survivors, focus groups and interviews were conducted as part of a practice-research engagement with a domestic violence shelter. All of the participants had been strangled and, among them, almost all were strangled multiple times. The loss of consciousness was common. Participants associated "choking" with use of body parts and "strangling" with use of objects. Although some minimized the assault, most considered strangulation to be serious and reported a variety of medical conditions following the assault. Few sought medical care. Of those who did, few disclosed the assault, or were asked about strangulation, which commonly resulted in misdirected treatment. Implications for improving detection and treatment are discussed.
\end{abstract}

Key words: women, strangulation, choking, intimate partner violence, health 


\section{INTRODUCTION}

Strangulation is a common and dangerous form of intimate partner violence (IPV) against women (Berrios \& Grady, 1991; Glass et al., 2008; Wilbur et al., 2001). It can induce loss of consciousness within seconds and brain death within minutes (Strack \& McClane, 1999). Prior nonfatal strangulation is associated with seven-fold odds of becoming an intimate partner homicide victim (Glass et al., 2008). It can lead to stroke, even weeks afterwards (Malek et al., 2000; Milligan \& Anderson, 1980), and to other substantial physical (e.g., throat and neck injuries, breathing problems), neurological (e.g., loss of sensation, speech problems) and psychological (e.g., PTSD, insomnia) problems (Strack \& McClane, 1999; Strack, McClane, \& Hawley, 2001; Wilbur et al., 2001). The number of strangulations is positively associated with the frequency of negative health outcomes (Smith, Mills, \& Taliaferro, 2001).

Unlike other forms of physical violence, strangulation often leaves no external evidence (Funk \& Schuppel, 2003; Strack \& McClane, 1999; Strack, McClane, \& Hawley, 2001; Taliaferro, Hawley, McClane, \& Strack, 2009). Even if redness is present upon initial examination, it does not necessarilydevelop into a dark bruise, and the bruises themselves regularly do not appear for hours or even days (Ikeda, Harada, \& Suzuki, 1992; Strack \& McClane, 1999). In addition, such marks and bruises can be difficult to observe on survivors with darker complexions (Baker \& Sommers, 2008; Strack, McClane, \& Hawley, 2001). Stableappearing survivors with no obvious marks on the skin may have serious internal injuries (e.g., laryngeal fractures), which, if not treated, can lead to morbidity and death (Funk \& Schuppel, 2003; Strack \& McClane, 1999; Taliaferro et al., 2009).

Despite the potential for death, many IPV victims who are strangled survive (Taliaferro et al., 2009). Research is needed to explore women's perceptions about the seriousness of 
strangulation as a form of IPV, the ways in which they think strangulation has affected their health, and the nature of their interactions with the health care system. Such information is important to improve detection and treatment, and to facilitate survivor self-care and follow-up. In addition to physical health effects, nonfatal strangulation affects one's mental health (Smith et al., 2001). Given its potential lethality, the act of strangulation symbolizes an abusive partner's power and control over the victim. The victim is overwhelmed by the abuser, vigorously struggles for air, and is at the mercy of the partner. According to Banzett and Moosavi (2001, para. 1), "there are few, if any, more unpleasant and frightening experiences than feeling short of breath without any recourse." Thus, it is not surprising that strangulation survivors report nightmares, depression, anxiety, and suicidal ideation (Smith et al., 2001).

Strangulation is often referred to as choking (Strack \& McClane, 1999); however, it is a misnomer. Choking involves internal blocking of the trachea by a foreign object that can impede oxygen intake (Strack \& McClane, 1999; Taliaferro et al., 2009). In strangulation, external pressure obstructs oxygen transportation to and from the brain due to the compression of blood vessels or air passages of the neck (Strack \& McClane, 1999; Taliaferro et al., 2009). Standardized measures that screen for IPV victimization and estimate lethality risk (e.g., The Revised Conflict Tactics Scale [see Straus, Hamby, Boney-McCoy, \& Sugarman, 1996] and The Danger Assessment Scale [see Campbell, Webster, \& Glass, 2009]) use “choke” rather than strangle. We do not know, however, if and how battered women distinguish these terms when describing their experiences.

Informed by the identified gaps in the extant literature, the current study used interviews and focus groups to explore women's perceptions and experiences of intimate partner strangulation. Qualitative methods have particular utility for exploratory investigations: 
interviews provide the opportunity for participants to describe their thoughts and experiences in their own words (Reinharz, 1992) and focus groups facilitate participant discussions that can yield insights that are new to both individual participants and researchers (Morgan, 1996). Given that most studies of intimate partner strangulation have been based on data collected in surveys and police records (Strack et al., 2001; Wilbur et al., 2001), the current investigation provides a valuable addition to the literature.

\section{METHODOLOGY}

The Approach

Beginning with the early stages of this study, we adopted a practice-research engagement approach (Brown, Bammer, Batliwala, \& Kunreuther, 2003). Practice-research engagements encompass a "wide range of interactions that involve reciprocity and space for learning" (Brown et al., 2003, p. 83). Such engagements, whether limited to an event or involving long-term collaborations, allow researchers and practitioners to learn together, and build insights and practical solutions to problems of common interest (Brown et al., 2003). A brief summary of the process we used follows.

In the winter of 2008 , the three authors attended an in-service presentation by the city medical examiner on detecting strangulation. The presentation was initiated by the city's Women's Death Review Team (of which the third author was a member) and attended by local domestic violence advocates and members of the District Attorney's office. As a follow-up, two of the authors convened meetings with attendees, other researchers, and interested agencies to discuss ways to improve detection and response to survivors of intimate partner strangulation. As researchers, our role was to supplement advocates' practice-based knowledge about 
strangulation. Upon invitation from the director of the city's sole domestic violence shelter, the first author prepared and presented the findings of a thorough literature review on strangulation at the agency's annual all-staff meeting. With support from the shelter director, the first author then presented the plan for a study, to be conducted in the shelter, to address the knowledge gaps uncovered during the meetings and the literature review.

The study began after we secured support from all staff that has direct contact with clients (i.e., counselors, case managers, and social work interns) and approval from the university's Institutional Review Board. Staff members were supportive of the proposed project. For staff engaged with victims on a daily basis, limited time and technical skills necessary for locating, adapting, and applying relevant research findings impede research-informed practice.. Practitioners rank accessible, locally-situated research that aligns with agency and staff interests as more useful for their practice than "hunting down and reading volumes of academic literature" (McLaughlin, Rothery, Babins-Wagner, and Schleifer, 2010, p.161).

We believe that our efforts to bring research and practice closer together have been successful. As a result of the first author's initial presentation, the participating agency added information about strangulation to its 40-hour domestic violence training. Also, using findings of the current study, we worked with the agency to develop tailored trainings for agency staff, outside social workers, attorneys, and city law enforcement officers. Such trainings reflect an integration of the major components of evidence-based practice: research evidence, practitioner expertise, and client experiences (Haynes, Devereaux, \& Guyatt, 2002).

Recruitment and Screening

We recruited adult women who had experienced physical abuse by a male partner in the past year via fliers posted at the domestic violence shelter. Fliers did not mention strangulation. 
Using questions adapted from the Revised Conflict Tactics Scale, volunteers were screened for physical abuse by a male partner (Straus, et al., 1996). A screening question specific to strangulation was developed with input from the city medical examiner, researchers, and battered women's advocates. Itwas: "In the last twelve months, has an intimate partner ever tried to physically assault you by choking you, or putting his hands around your throat and squeezing it, or putting a piece of clothing/wire/cord around your throat and pulling it tightly?" Probes about medical conditions were guided by the pioneering work of Strack, McClane, and Hawley (2001). .

Data Collection

A focus group and interview guide was developed by the authors then, during June-July 2009, the first author conducted two focus groups and eight in-depth interviews in a private room at the shelter. Participants were asked for verbal rather than written consent, as required by the university IRB to maintain anonymity. Of the 21 eligible volunteers, 17 participated. Nine women participated in two focus groups, and eight participated in interviews. Sessions lasted 90120 minutes each, and participants were compensated with a \$30 gift certificate. Clinical social workers were available to provide support in case a participant was distressed during or after the session.

The semi-structured interviews and focus groups focused on the nature of the women's intimate relationships, their experiences of and perceptions about strangulation as a form of IPV, their use of terms choking and strangling, the impact of strangulation on their life, and their helpseeking efforts. A brief demographic questionnaire was administered at the start of the session. In addition, the interviewer obtained permission to audiotape the session and assured women of 
the confidentiality of their responses. On completion of the session, the interviewer shared information about strangulation with the participants.

Participants ranged in age from 21-47 years and all had children. Fourteen self-identified as African American, two as White, and one as West Indian. Two women had not finished high school, eight had completed high school, and seven had attended some college, vocational training, or had completed college. Three were married, four were divorced, and the remaining were single. Thus, the women were diverse in terms of ethnicity, education, and marital status. Change in the Original Study Plan

In the original study design, we planned to conduct three focus groups. One group would be with abused women who reported never experiencing strangulation, another with abused women who reported at least one strangulation experience, and a mixed group (i.e., those who had and those who had not been strangled). We were interested in whether women who did not reported having been strangled would remember, re-label, or otherwise reconsider any strangulation experiences during the course of the focus group. We had to alter the plan, however, as all but one of the women reported that they strangled. Thus, we conducted two focus groups of abused women, all of whom had experienced strangulation.

Data Analysis

We used grounded theory (Strauss \& Corbin, 1990) to organize and analyze the data, which consisted of information gathered during the focus groups and interviews and notes made during or immediately after the screenings, interviews, and focus groups. The audiotapes were transcribed by either a research assistant or by the transcription agency we hired; none of the transcribers had contact with the study participants during the data collection phase. To check for 
transcriber accuracy, the second author listened to 10 minutes of each recording. Transcripts with discrepancies were re-transcribed by the same author.

We used an iterative process of coding, first line-by-line using open coding and then a focused approach using axial coding (Strauss \& Corbin, 1990). This process facilitated the organization and integration of data sections and resulted in the identification of several general themes. We also tallied the frequency of reported physical and mental health conditions. The first author performed the initial coding then the second author analyzed the transcripts and compared her codes and categories with those of the first author. Findings presented herein pertain to the themes related to health effects and help-seeking; illustrative quotes are provided.

\section{FINDINGS}

Frequency and Characteristics of the Strangulation Assaults

Strangulation was a recurring form of IPV in the women's lives. Most (15 of 17) had been strangled multiple times. One woman was strangled twice in the same incident: "if he could not black me out, he'd let me go for a little bit, then turn around and do the same shit all over again." Women typically were in vulnerable circumstances when strangled: two were sleeping, two were grabbed from behind, and four were pregnant. The abusive partners most often used manual strangulation (i.e., hands, forearms, legs); some used objects (e.g., telephone cord, shoe laces, a wooden board). Although we did not ask specifically about it, about one fourth of the women offered that they were strangled during pregnancy.

Most (14 of 17) women lost consciousness, and two others reported being "close to blacking out," indicating complete or partial lack of oxygen to the brain (Valera \& Berenbaum, 2003). One woman reported her experience as she was losing consciousness: "It was crazy...I literally saw my face and my life flashing before my eyes." 
Strangulation was accompanied by verbal abuse and other physical violence. One woman said: “It wasn't just choking by itself. There were other things being done to me. I've had my body thrown against walls and sinks and tubs. And in the midst of that - not saying every single time - I remember that as the incident [one of the incidents] where he choked me." Not surprisingly, it was difficult for women, in their conversations, to focus only on strangulation. In a majority of cases, strangulation appeared following an increase in the severity and frequency of abuse and other markers of IPV lethality.

"Strangling" vs. "Choking"

Women clearly differentiated between "choking" and "strangling," but their definitions deviated from the medical definition. They indicated that both involve the application of external pressure to the throat, but that choking occurs when hand(s) and/or body parts are used and strangling occurs when objects are used. One woman explained, "Strangulation is usually done with something... a rope, a belt, wires or something. You're usually hanging when you're strangled. But when you're choked, they use their hands." Another woman said:

Well, strangling I believe, my concept of strangling, is like a cord or something wrapped around the person's neck. And choking is like actually taking their force and their anger and that energy and just placing their hands upon someone's neck and gripping it tighter. Regardless of the term they used, most women described strangulation as a serious form of violence. One woman said, “They're all serious. One blow to the head can kill us. One minute too long without oxygen would kill us, too.” At times, however, it appeared that the survivors minimized the behavior. For example, one woman explained,

He choked me, I'm not going to defend that...he choked me until I passed out...but the reality is that when he choked me he only did it once...I'm not a victim of somebody that 
just obsessively chokes me...I'm with somebody that choked me just once...I didn't have to go to the hospital.

\section{Recognition of Health Effects}

Upon initial questioning, few participants linked strangulation to the variety of medical conditions that emerged after the incident or that continued to affect them. Upon further probing, however, they began to identify the ways in which they believed strangulation had impacted their immediate and long-term health. One participant initially spoke of the strangulation incident as not serious - "The choking scene was just like 'Okay, you put your hands on me"” - but later said that the strangulation incident caused her to lose consciousness and bladder control.

Participants described conditions that appeared immediately or within days of the assault and persisted for days, weeks, or months. Each woman reported developing at least one problem, with a majority indicating several conditions. One woman could not speak for days after her partner strangled her with a wooden board. A few believed that, although months had passed, they still had problems linked to the incident. One woman said: "I got my tonsils removed last year, but I still get [a] sore throat ... it make no sense, [the doctors said] 'well you don't have a virus, you don't have this,' so they could not say why my glands get swollen.”

Participants ultimately discussed a range of immediate and persistent health effects that they believed were a result of or exacerbated by strangulation (see Table 1). Physical effects included difficulty swallowing, voice changes, and neck pain. One woman said, "I had swelling. It was really painful to swallow. It felt like somebody just cut my whole throat.” Another, who was strangled severely enough to require hospitalization, described how her voice changed: "I used to have the sweetest voice and, like, even on the phone now, I sound really raspy. It stems from that." Another had abrasions on as well as swelling of the neck: "I don't know what he 
choked me with, but I had scratches, and the scratches started swelling, and they turned into like [spider] webs, and there was some bleeding and, like, I didn't even know I could turn colors.”

Neurological manifestations included ringing in the ears (tinnitus), physical weakness, and loss of consciousness. One woman linked having a stroke to being strangled: "Well that's when I had my stroke...There was an incident where I went through a thing with him, and he beat me up real bad and he choked me and that very night I had a stroke." Another woman spoke of the possible indirect effects of strangulation: "And the thing about it [strangulation] as far as a health issue, it's bad on me because maybe that's one of the reasons why my blood pressure stays so high. Like 170 over 110 or 140 is no good."

Participants also described psychological problems including nightmares, insomnia, anxiety, and heightened and persistent fear. Some women reported that existing problems such as depression, anxiety, and suicidal ideation worsened after strangulation. One woman's nightmares began immediately after the first assault:

I thought he was gonna kill me in my sleep. Sometimes I had dreams that he shot me in the head - in the back of the head - I was trying to run from him, and I was in a car and he was following me.

Women's mental health problems regularly continued beyond the abusive relationship into a new intimate relationship. For instance, one woman explained,

When I first started dating this new guy, I would flinch every time he touched me...I was sitting on the bus and he went to go and put his arm around me like that, around my neck kind of. I flipped out. I was like - 'don't you ever try to choke me.' I made this big scene in the bus. It was so embarrassing.

Health Care System Contact 
Fewer than half of the participants sought medical care for strangulation-related injuries. Their interactions with medical providers reveal complicated situations and several barriers to disclosure and detection.

A quarter of the participants who sought health care disclosed voluntarily that they had been strangled. One woman reported medical indifference: "He [doctor] just told me eat popsicles or drink warm tea. [Interviewer: did you tell him what happened?] Yes, I told him...he just gave me some Tylenol or Motrin. That was it...nothing, they don't do nothing." The other participant reported that medical providers were helpful because, even though there was little they could do medically for her neck injury, they tried to relocate her to a safe place.

Two participants were hospitalized with severe strangulation-related injuries that made detection easy. One of the two complied with all medical exams, a police report, and follow-up photographs. Physicians suggested that the other woman call the police, but she refused: "I was threatening to leave the hospital if they did that. To be honest with you I was scared, like, you never know what he might do." A few months later, after relocating to a different city for safety reasons, she told her prenatal care doctor about being strangled and found it useful:

When I was getting the information and a better insight on what could possibly happen... I explained exactly what happened and how I peed on myself. I could have been dead, you know. That was a wake-up call, and it was so scary just to hear that come out of the doctor's mouth, but it was real.

Half of those who sought health care after being strangled neither disclosed strangulation nor were asked about it. Misdiagnoses and erroneous treatment plans followed. One woman said, “They gave me the notion that I did have bronchitis...so I'm taking all the medicines thinking I got bronchitis and I am allergic to the medicine...so my whole mouth swelled up." Another said, 
"The pain lasted for a couple of days...swallowing was painful...the doctor said that I should get a thyroid exam...I never went for it...it wasn't my thyroid...I knew what happened."

Participants who did not seek medical help or who did not disclose strangulation offered various reasons for doing so. They reported wanting to get to a safe place first and then tend to their health. Other reasons included feeling reluctant to share such a personalexperience, not knowing anyone who disclosed abuse to a physician, and because the abusive partner was in the medical provider's office. One woman believed that unless medical providers were more equipped for action, they would not be very helpful: "Unless they're able to at that moment be able to take you somewhere safe and keep you there, there's really nothing that they can do other than what they're already doing, which is asking 'do you want help?'”

\section{DISCUSSION}

Strangulation appears to be common and recurring among women who seek shelter from an abusive partner. All but one of the battered women we spoke with had been strangled by a male intimate at least once in the past year. Most (82\%) had been strangled multiple times.

Our study is the first, to our knowledge, to assess how strangulation survivors label the behavior of their abuser. Rather than relying on the medical definitions of "strangling" and "choking", women differentiated between the two based on the mechanism used. If hands or other body parts were used; they referred to it as "choking"; if objects were used, they referred to it as "strangling." It is important to stress that women did not use these terms interchangeably, but spoke of them as different abuse tactics. Probing with the terminology used by survivors may be important when screening for IPV-related strangulation; more on this will follow. 
Our study is, to our knowledge, the first investigation to ask women to express their thoughts on the seriousness of strangulation. In general, women answered affirmatively when asked about seriousness, however, some depicted the incident as not serious enough to warrant alarm or action. Minimizing violence severity or frequency is not uncommon among battered women; it is sometimes viewed as a coping method (Anderson \& Saunders, 2003). Given that strangulation can be lethal in minutes and our finding that few women initially associated strangulation with subsequent medical conditions is cause for concern, particularly given that mostwere strangled multiple times.

Study participants reported a variety of medical conditions - from loss of consciousness to stroke - that they thought were associated with having been strangled. Common physical complaints included sore throat, neck pain and swelling, voice change, and difficulty in swallowing. These findings buttress those of prior research (Smith et al., 2001; Wilbur et al., 2001). Such complaints can become more frequent with an increase in the cumulative number of assaults (Smith et al., 2001).

Similarly, participants described experiencing several negative mental health consequences due to strangulation, all of which have been identified in prior research (Smith, et al., 2001). The fear of being strangled led some women to have nightmares and develop an almost hyper vigilance about protecting the neck from close contact. Although we did not assess for PTSD, the experience of strangulation meets both of the DSM-IV criteria for a traumatic event (i.e., the threat of death and experience of intense fear or helplessness; American Psychiatric Association, 2000). Additional research with larger samples is needed to explore the myriad ways in which strangulation impacts mental health. 
Fewer than half of the women who had been strangled sought medical help. Those who went to a provider rarely disclosed abuse due to fear, discomfort discussing it, and, in a few cases, because the abuser was present. Providers rarely asked about strangulation. Nondisclosure and lack of inquiry at times led to misdiagnosis and the formulation of inappropriate treatment plans.

Our findings are based on self-reports, which, although limited by women's decisions to disclose experiences and their memories of the strangulation assaults, is also a strength of the study. Women provided rich details about their experiences with strangulationV and helpseeking which can help improve systemresponse.

Implications for Practitioners

Despite experiencing a variety of health problems, women initially did not recognize the changes that occurred after strangulation. Thus, neither the patient nor a standard medical history may reveal the underlying cause of a diverse set of symptoms. Given that multiple strangulations appear to be common and can increase the risk of long-term health problems, documenting a history of strangulation may help in the formulation of appropriate treatment plans. In addition, once recognized, such patients, given their high risk of homicide (Campbell, et al., 2007), must be connected to a medical social worker who can link them with shelters and other support services.

Our findings indicate that if we had asked only about choking, we may have missed experiences of being strangled with objects. Given that abused women used the terms "choking" and "strangulation" differently, it may be useful to ask a behaviorally-specific question(Laughon, Renker, Glass, \& Parker, 2008). A shortened version of the screening question used in this study has promise: "Has a partner tried to assault you by putting his hands around your throat and squeezing it or by putting a piece of clothing/wire/cord around your throat and pulling it 
tightly?" Such practices may improve disclosure and appropriate examination (for guidance on clinical management, see McClane et al., 2001)

When IPV victims have visible injuries, police called to the scene typically transport them to an emergency department. With strangulation, however, external marks may not be visible immediately after an assault. Participants reported that the presence of visible marks varied with each incident; those who suffered multiple strangulations had visible marks in some incidents and faint or no marks in others. Thus, health care providers and social workers cannot rely on law enforcement as the way in which they will be alerted to strangulation survivors.

Although some survivors seek care in emergency departments, it is misguided to assume that emergency departments are the sole, or even primary, setting to which strangulation survivors may present. Diffuse symptoms (e.g., a sore throat, difficulty swallowing) may lead strangulation victims to see primary care physicians, dentists, and other health care providers. Moreover, mental health consequences such as anxiety, nightmares, and insomnia suggest that clinical social workers both within and outside medical settings may encounterclients with the symptoms of strangulation. We recommend that all professionals who attend to the needs of abused women, regardless of setting, be trained on intimate partner strangulation.

Despite the abuse they endured, study participants reported that they kept their prenatal care appointments. On average, pregnant women are seen for 12 or 13 prenatal visits (Centers for Disease Control, n. d.). Thus, pregnancy provides a window of opportunity in which medical specialists and social workers in medical settings can build trusting relationships with patients, identify patients experiencing IPV, and connect them to the appropriate services. Others have suggested that a query about "choking" should be added to routine screening questions used during pregnancy (Bullock, Bloom, Davis, Kilburn, \& Curry, 2006). Our findings suggest that 
adding a behaviorally specific question, as noted above, may be even more useful. Such action may be warranted, as strangulation may be more common than other forms of physical violence during pregnancy (Bullock et al., 2006).

Detection will continue to be an issue due to limited provider time, lack of training, and patient nondisclosure. In particular, for stroke patients, such as the young woman in our study, including questions about intimate partner strangulation may be important, especially in the absence of other causal explanations (Malek, Higashida, Phatouros, \& Halbach, 1999). The use of prompts, reminders, questionnaires, and other office system methods may help promote inquiry about IPV and desired preventive behavior (e.g., referral to shelters; Bansal, Park, \& Edwardson, 2008). A team approach that involves everyone along the health care chain (i.e., physicians, nurses, health assistants, and social workers), is needed to ensure health and safety for victims of such serious forms of violence. Such attempts at coordinated care for the detection of IPV have demonstrated positive results (e.g., Short, Hadley, \& Bates, 2002).

Health care outside of traditional medical settings may be another avenue for the detection and treatment of strangulation. As one participant asserted: "We need health care at this shelter. At the shelter in [name of another city] there was a central medical clinic that dealt with everything." Women who disclose a recent strangulation experience might need immediate medical attention, yet domestic violence shelter staff may not be aware of the pervasiveness of strangulation among their clientele, the associated health risks, or the need for immediate response. Findings from a multi-state study on the needs of domestic violence shelter residents indicate that health care is a common request that often goes unmet (Lyon, Lane, \& Menard, 2008). Again, a collaborative approach may be useful: health care providers can assist shelters by increasing their medical outreach and training shelter staff so as to facilitate early detection and 
treatment. Holding health fairs in shelters and improving referral mechanisms that link shelters with health care services may encourage women to seek medical care sooner, improve follow-up, and facilitate self-care.

\section{CONCLUSIONS}

A history of multiple strangulations appears to be common among residents of a battered women's shelter. It is not, however, limited to women who seek shelter from an abusive partner or to residents of the U.S. (Djikanovic, Jansen, \& Otasevic, 2010; Nguyen, Ostergren, \& Krantz, 2008). Numerous physical, neurological, and psychological problems are associated with strangulation. Thus, strangulation in the context of IPV, regardless of victim residence, warrants increased attention. Screening using a behaviorally-specific question (rather than using the word "choked" or "strangled") may yield previously unidentified survivors of strangulation who may not link their health conditions to the assault(s). Detection, a responsibility that rests in the hands of every professional who works with battered women, may facilitate the development of appropriate treatment plans or, at least, reduce misguided treatment. 


\section{REFERENCES}

American Psychiatric Association. (2000). Diagnostic and statistical manual of mental disorders (4th ed., text rev.). Washington, DC: Author.

Anderson, D. K., \& Saunders, D. G. (2003). Leaving an abusive partner: An empirical review of predictors, the process of leaving, and psychological well-being. Trauma, Violence, \& Abuse, 4, 163-191.

Baker, R. B., \& Sommers, M. S. (2008). Physical injuries from intimate partner violence: Measurement strategies and challenges. Journal of Obstetric, Gynecologic, \& Neonatal Nursing, 37, 228-233.

Bansal, S. K., Park, E., \& Edwardson, E. A. (2008). Medical inquiry for intimate partner violence as reported by women in a shelter. Journal of Emergency Medicine, 34, 341-345.

Banzett, R. B., \& Moosavi, S. H. (2001). Dyspnea and pain: Similarities and contrasts between two very unpleasant sensations [Electronic Version], APS Bulletin, 11(1).

Berrios, D. C., \& Grady, D. (1991). Domestic violence: Risk factors and outcomes. Western Journal of Medicine, 155, 133-135.

Bullock, L., Bloom, T., Davis, J., Kilburn, E., \& Curry, M. A. (2006). Abuse disclosure in privately and Medicaid-funded pregnant women. Journal of Midwifery \& Women's Health, 51, 361-369.

Brown, D. L., Bammer, G., Batliwala, S., \& Kunreuther, F. (2003). Framing practice-research engagement for democratizing knowledge. Action Research, 1, 81-102.

Campbell, J. C., Glass, N., Sharps, P. W., Laughton, K., \& Bloom, T. (2007). Intimate partner homicide: Review and implications of research and policy. Trauma, Violence, \& Abuse, 8 , 246-269. 
Campbell, J. C., Webster, D. W., \& Glass, N. (2009). The Danger Assessment: Validation of a lethality risk assessment instrument for intimate partner femicide. Journal of Interpersonal Violence, 24, 653-674.

Centers for Disease Control. Intimate partner violence during pregnancy. Retrieved from http://www.cdc.gov/reproductivehealth/violence/IntimatePartnerViolence/sld001.htm.

Copelon, R. (1994). Recognizing the egregious in the everyday: Domestic violence as torture. Columbia Human Rights Law Review, 25, 291-367.

Djikanovic, B., Jansen, H. A., \& Otasevic, S. (2010). Factors associated with intimate partner violence against women in Serbia: A cross-sectional study. Journal of Epidemiology \& Community Health, 64, 728-735.

Funk, M., \& Schuppel, J. (2003). Strangulation injuries. Wisconsin Medical Journal, 102, 41-45.

Glass, N., Laughon, K., Campbell, J. C., Wolf, A. D., Block, C. A., Hanson, G., et al. (2008). Non-fatal strangulation is an important risk factor for homicide of women. Journal of Emergency Medicine, 35, 239-235.

Haynes R. B., Devereaux P.J., \& Guyatt G. H. (2002). Clinical expertise in the era of evidencebased medicine and patient choice. Evidence Based Medicine, 7, 36-38

Ikeda, N., Harada, A., \& Suzuki, T. (1992). Homicidal manual strangulation and multiple stungun injuries. American Journal of Forensic Medicine and Pathology, 13, 320-323.

Laughon, K., Renker, P., Glass, N., \& Parker, B. (2008). Revision of the abuse assessment screen to address nonlethal strangulation. Journal of Obstetric, Gynecologic, \& Neonatal Nursing, 37, 502-507.

Lyon, E., Lane, S., \& Menard, A. (2008). Meeting survivor's needs: A multi-state study of domestic violence shelter experiences. Washington, DC: National Institute of Justice. 
Malek, A. M., Higashida, R. T., Halbach, V. V., Dowd, C. F., Phatouros, C. C., Lempert, T. E., et al. (2000). Patient presentation, angiographic features, and treatment of strangulationinduced bilateral dissection of the cervical internal carotid artery. Journal of Neurosurgery, 92, 481-487.

Malek, A. M., Higashida, R. T., Phatouros, C. C., \& Halbach, V. V. (1999). A strangled wife. Lancet, 353,1324.

McClane, G. E., Strack, G. B., \& Hawley, D. A. (2001). A review of 300 attempted strangulation cases Part II: Clinical evaluation. Journal of Emergency Medicine, 21, 311-315.

McLaughlin, A., Rothery, M., Babins-Wagner, R., \& Schleifer, B. (2010). Decision-making and evidence in direct practice. Clinical Social Work Journal, 38, 155-163.

Milligan, N., \& Anderson, M. (1980). Conjugal disharmony: A hitherto unrecognized cause of strokes. British Medical Journal, 81, 421-422.

Morgan, D. L. (1996). Focus groups. Annual Review of Sociology, 22, 129-152.

Nguyen, D. V., Ostergren, P. O., \& Krantz, G. (2008). Intimate partner violence against women in rural Vietnam: Different socio-demographic factors are associated with different forms of violence. BMC Public Health, 11, 8-55.

Reinharz, S. (1992). Feminist methods in social research. New York: Oxford University Press.

Short, L. M., Hadley, S. M., Bates, B. (2002). Assessing the success of the WomanKind program: An integrated model of 24-hour health care response to domestic violence, Women \& Health, 35(2/3), 101-119.

Smith, D., Mills, T., \& Taliaferro, E. H. (2001). Frequency and relationship of reported symptomology in victims of intimate partner violence: The effect of multiple strangulation attacks. Journal of Emergency Medicine, 21, 323-329. 
Strack, G. B., \& McClane, G. E. (1999). How to improve your investigation and prosecution of strangulation cases. Retrieved from http://www.ncdsv.org/images/strangulation_article.pdf.

Strack, G. B., McClane, G. E., \& Hawley, D. (2001). A review of 300 attempted strangulation cases Part I: Criminal legal issues. Journal of Emergency Medicine, 21, 303-309.

Straus, M., Hamby, S. L., Boney-McCoy, S., \& Sugarman, D. B. (1996). The revised Conflict Tactics Scales (CTS2): Development \& preliminary psychometric data. Journal of Family Issues, 17, 283-316.

Strauss, A., \& Corbin, J. (1990). Basics of qualitative research. Newbury Park, CA: Sage.

Taliaferro, E., Hawley, D., McClane, M., \& Strack, G. (2009). Strangulation in intimate partner violence. In C. Mitchell \& D. Anglin (Eds.), Intimate partner violence: A health-based perspective (pp. 217-325). New York: Oxford University Press.

Valera, E. M., \& Berenbaum, H. (2003). Brain injury in battered women. Journal of Consulting and Clinical Psychology, 71, 797-804.

Wilbur, L., Highley, M., Hatfield, J., Surprenant, Z., Taliaferro, E., Smith, D., et al. (2001). Survey results of women who have been strangled while in an abusive relationship. Journal of Emergency Medicine, 21, 297-302. 
Table 1. Immediate and persisting post-strangulation physical, neurological, and psychological health problems

\begin{tabular}{lll}
\hline \multicolumn{1}{c}{ Physical and neurological } & & Psychological conditions \\
\cline { 1 - 1 } Petechiae & & Insomnia \\
Red marks on the neck & & Nightmares \\
Scratches on the neck & Anxiety \\
Ligature marks & & Depression \\
Bleeding & & Suicidal ideation \\
Neck swelling & Extreme fear \\
Tongue swelling & Fear of being alone \\
Sore throat & Panic attacks \\
Difficulty swallowing & \\
Voice changes & \\
Hoarseness & \\
Neck pain & \\
Back pain & \\
Difficulty breathing & \\
Difficulty being in a supine position & \\
Vomiting & \\
Heartburn & \\
Loss of appetite & \\
Pain in pregnant abdomen & \\
Tinnitus & \\
Dizziness & \\
Feeling nauseous & \\
Loss of consciousness & \\
\hline
\end{tabular}

